Dina Kh. Rybalkina, Lyazat K. Ibrayeva, Bakyt M. Salimbaeva, Larissa S. Minbayeva,

Irina V. Bacheva, Yelena A. Drobchenko, Natalya Yu. Aleshina

\title{
ASSESSMENT OF MEDICAL AND SOCIAL LOSSES DUE TO SOCIALLY SIGNIFICANT DISEASES IN THE EAST KAZAKHSTAN REGION
}

\author{
Karaganda Medical University
}

\begin{abstract}
AIMS. The aim of the research was assessment of the medical and social losses due to socially significant diseases (malignant neoplasms and diseases of the circulatory system) in population living in the ecologically unfavorableregion of Kazakhstan (East Kazakhstan Region (EKR)).

MATERIALS AND METHODS.The materials for the research were provided by the Department of Statistics, the Republican Center of Electronic Health Care and the Regional Oncology Center for 5 years depth (2011-2015 yy.). Statistical data of the entire population of the region was analyzed.

Years of Life Lost (YLL), YLL due to death integral indicators were calculated according to the standardized methodology recommended by the World Health Organization (WHO).

RESULTS AND CONCLUSION. Significant premature loss of years due to socially significant diseases in the study region was observed in the research group of 45-69 years with a gender prevalence in male. The fraction of direct economic loss as a result of health losses due to circulatory system diseases and malignant neoplasms averaged about 5\% of the Gross Domestic Product (GDP). The medical and social losses of years depend on a number of social and economic factorsin the region (environmental pollution, population income, centralized water supply and the fraction of economically active population).
\end{abstract}

Key words: demography, premature mortality, loss of years, social and economic factors

\section{INTRODUCTION}

The main indicator of the medical and demographic processes of society is mortality that reflects many aspects. Premature mortality reduces life expectancy. Having the generalized statistical indicators without appropriate methodological studies based on the data about health status of separate population groups (particularly, the Years of Life Lost indicator (YLL)), it is very difficult to distinguish the role and importance of each of the listed factors (1-2).

YLL is widely used by epidemiologists around the world. The advantage of this indicator is its integrative nature. It provides a multidimensional analysis of mortality, increases the level of awareness, measurability and comparability of estimates. It helps to assess mortality in the break down on separate causes and minding the structure of mortality by gender, age, and time period. YLL index measures mortality by the number of lost years of life. It allows to use YLL for assessment of social and economic losses from premature mortality.
Decrease of the YLL index during a period oftime may be considered as a positive result of health care activities, social and economic policies (3-4).

Solving the problems of health status and life expectancy of population is a strategic task of every country. Currently, at the most industrialized regions of the Republic of Kazakhstan (RK), the situation associated with increase of the influence of various risk factors on public health has arisen. In this regard, within the framework of scientific and technical program (STP) "Development of scientific and methodological foundations for environmental load minimizing, improvement of medical care, social protection and rehabilitation of the population of ecologically unfavorable regions of the Republic of Kazakhstan", the state of health of individuals in several regions of the RK in relation to social and economic factors was analyzed (5).

For 2000-2015 yy., mortality in the EKR $(12.1 \pm 0.6$ $\%$, CI 95\% 11.7-12.6) was 1.3 times evidently higher than the long-term average annual in the RK $(9.3 \pm 0.7$ $\%$, CI 95\% 8.9-9.8) (6). For 2000-2015 yy., mortality due to circulatory system diseases (CSD) dominated 
in the structure of total mortality, averaging $44.3 \%$ over the RK, and $46.5 \%$ in the EKR. It significantly exceeded republican indicators with a relative risk of 1.4 times. Mortality due to malignant neoplasms (MN) exceeded republican indicators with a relative risk of 1.5 times, that requires a more detailed research.

The aim of the research was assessment of the medical and social losses due to socially significant diseases, leading in the mortality structure (MN and CSD) in population living in the ecologically unfavorable region of Kazakhstan (the East Kazakhstan Region (EKR)).

\section{MATERIALS AND METHODS}

The materials for the research were provided by the Department of Statistics, the Republican Center of Electronic Health Care and the Regional Oncology Center for 5 years depth (2011-2015 yy.). Statistical data of the entire population of the region was analyzed. Statistical data of the entire population of the region was analyzed. The following demographic indicators were used: population in the age and gender aspect in absolute terms (age groups for male and female ( $0-4$, 5-14, 15-29, 30-44, 45-59, 60-69, 70-79, and over 80 years old), mortality due to CSD and MN in absolute terms in the age and gender aspect for similar groups.

Years of Life Lost (YLL) due to death integral indicators was calculated with the formula 1:

$$
\mathrm{YLL}=\Sigma \mathrm{Dx} * \mathrm{ex}
$$

Dx - the number of died at the age of $\mathrm{x}$; ex - life expectancy at the age of $\mathrm{x}$ (from standard mortality tables); $\mathrm{x}$ - age from 0 to 85 years and above.

To reflect the dependence of the value of health losses on age, the standard coefficient of discounting (0.03), index for correction (0.1658) and parameter that determines the form of the function that sets socially significant weights of various age groups (0.04) were used in the YLL index calculating (according to the WHO) (7).
To calculate social and economic losses the next indicators were used: indicator of the number of working people (in absolute terms), GDP per capita (in thousands of tenge); regional GDP (in thousands of tenge).The relationship between medical and social losses (YLL) and socially significant factors (social and economic indicators of the provision of the population with centralized water supply (in proportion), the number of economically active people aged 25-72 years (in absolute terms), and proportion of the population with incomes below the subsistence minimum) were determined by the Pearson correlation method.

\section{RESULTS}

In course of time, the loss of years due to mortality, caused by MN in the EKR tended to decrease (Figure 1). In the gender aspect, the loss of years due to caused by $\mathrm{MN}$ mortality in male was exceeded the loss of years in female by 1.3-1.4 times. So, in the RK male of working age die more often than female, which may be partly related with more severe physical exertion and harmful working conditions in the industrial region. For 2011-2015 yy. the fraction of workers, exposed to occupational hazards in the RK was $21.6 \%$, in the EKR $-27.5 \%$. The number of working in adverse conditions male workers exceeded the number of female workers by 1.9 times in the RK and 2.9 times in the EKR.

In the age aspect, the maximum loss of years was observed between the age groups of 70-79 years and 60-69 years (Table1). Losses of years in the age group 80 and older were approximately 2 times less than the previous groups. Moreover, the number of lost years of life sharply increased in the period from 45 to 59 years in both male and female. The minimum losses of years were recorded at the age group of 0-4 years. Similar losses of years were observed in the age groups of 5-14 years and 15-29 years. The loss of years in males of 30-44 years of age was 6.2 times less than the loss of years in the age group of 45-59 years. Losses of years

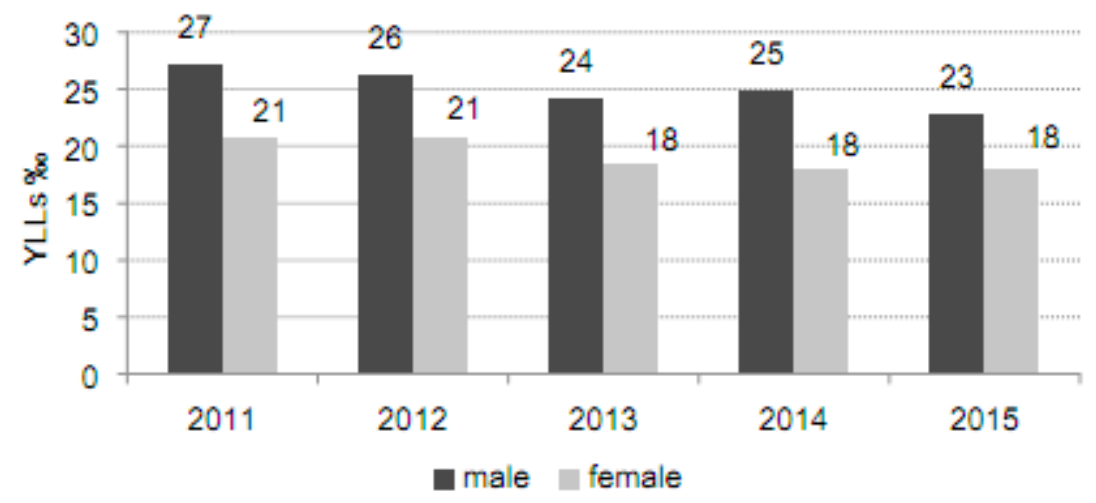

Fig. 1. Medical and social losses of years due to MN in the EKR. 
Table I. Losses of years due to MN (M \pm m\%o, CI 95\%) in the EKR for 2011-2015 yy.

\begin{tabular}{|c|c|c|c|c|c|c|}
\hline Age & Male & CI & Female & CI & Total & CI \\
\hline $0-4$ & $1.2 \pm 0.4$ & $0.1: 2.4$ & $1.7 \pm 0.5$ & $0.4: 2.9$ & $1.45 \pm 0.3$ & $1.2: 4.6$ \\
\hline $5-14$ & $1.5 \pm 0.2$ & $1.0: 2.0$ & $0.8 \pm 0.2$ & $0.4: 1.3$ & $1.15 \pm 0.1$ & $1.8: 2.9$ \\
\hline $15-29$ & $2.1 \pm 0.3$ & $1.3: 2.9$ & $2.3 \pm 0.4$ & $1.2: 3.3$ & $2.2 \pm 0.3$ & $2.6: 6.1$ \\
\hline $30-44$ & $7.7 \pm 0.4$ & $6.5: 8.8$ & $9.8 \pm 0.3$ & $9.1: 10.5$ & $8.75 \pm 0.3$ & $16.2: 18.7$ \\
\hline $45-59$ & $47.9 \pm 1.5$ & $43.8: 52.0$ & $35.4 \pm 1.3$ & $31.9: 38.9$ & $41.65 \pm 1.2$ & $77.0: 89.6$ \\
\hline $60-69$ & $120.6 \pm 4.8$ & $107.1: 134.0$ & $54.3 \pm 3.2$ & $45.3: 63.2$ & $87.4 \pm 3.9$ & $152.9: 196.8$ \\
\hline $70-79$ & $124.6 \pm 6.9$ & $105.3: 143.8$ & $60.1 \pm 3.3$ & $51.0: 69.2$ & $92.35 \pm 4.8$ & $157.3: 212.0$ \\
\hline $80+$ & $65.1 \pm 5.7$ & $49.3: 80.9$ & $26.8 \pm 3.1$ & $18.1: 35.5$ & $45.95 \pm 4.2$ & $68.5: 115.3$ \\
\hline Total & $25.0 \pm 0.7$ & $23.0: 27.1$ & $19.2 \pm 0.7$ & $17.3: 21.1$ & $22.1 \pm 1.2$ & $40.4: 48.0$ \\
\hline
\end{tabular}

in females of 30-44 years age group were 3.6 times less than in the group of 45-59 years.

Analysis of the structure of mortality due to MN showed that the main causes of death were $\mathrm{MN}$ of digestive $(57.2 \pm 1.7 \% 000)$ and respiratory $(33.8 \pm 1.0 \% 000)$ systems, followed by $\mathrm{MN}$ of female genital organs, mammary gland, lymphoid and hematopoietic tissues (Figure 2). 38.9\% of registered deaths due to $\mathrm{MN}$ occurred in the employable population. The structure of mortality due to $\mathrm{MN}$ for the employable population was similar to the structure of mortality for the entire EKR population.

To reveal the significant social and economic factors affecting the loss of years of life due to $\mathrm{MN}$, correlation was performed. Correlation analysis revealed statistically significant inverse relationships between the average loss of years per 1000 people and GDP per capita $\mathrm{r}=-0.94 \quad(\mathrm{p}=0.015)$. Also, statistically significant inverse relationships were observed between the loss of years due to premature death, caused by MN in males and females and GDP per capita $(r=-0.88 \quad(p=0.043), r=-0.95 \quad(p=0.013)$, respectively). The inverse correlation coefficient tells us that with an increase of GDP per capita, the loss of life years decrease. An inverse correlation was also found between the loss of years of life and the presence of centralized water supply $(\mathrm{r}=-0.9(\mathrm{p}=0.004), \mathrm{r}=-0.94$ $(\mathrm{p}=0.014), \mathrm{r}=-0.95(\mathrm{p}=0.013))$ (total loss of years, loss of years between males and females, respectively)). In addition, direct statistically evident relationship was found between the loss of years of life and the number of economically active population $(\mathrm{r}=0.89(\mathrm{p}=0.003))$,
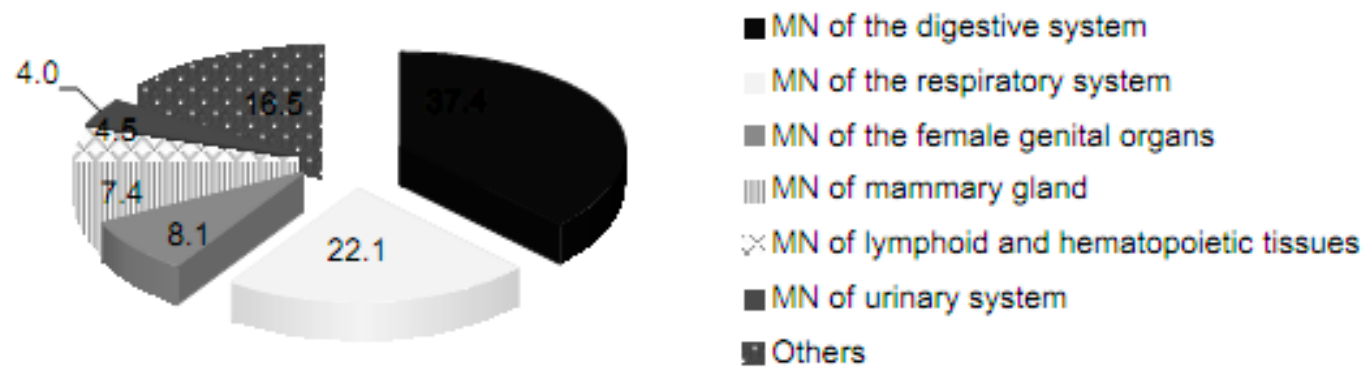

Fig. 2. The structure of mortality due to MN in the population of the EKR for 2011-2015 yy. (in \%).

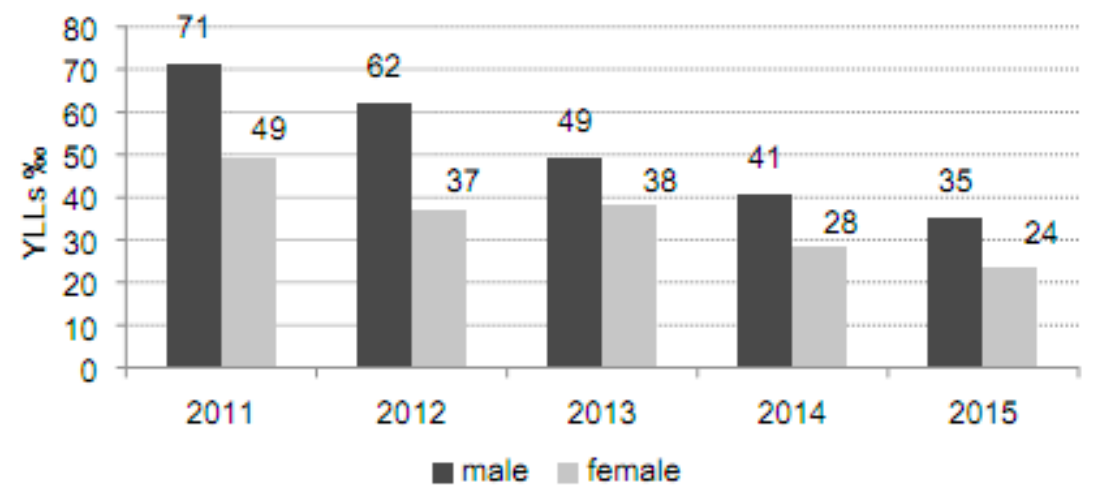

Fig. 3. Medical and social losses of years due to CSD in the EKR. 
for male $r=0.9(p=0.003)$. For females, the indicators were not statistically significant. A direct statistically evident relationship was also found between the loss of years of life and the fraction of population with incomes below the subsistence line $r=0.89(p=0.004)$. It was also significant only for males $\mathrm{r}=0.9(\mathrm{p}=0.003)$.

Decrease in the mortality rate due to CSD by 62.5 to $\%$ in the RKand by $55 \%$ in the EKR, with decrease in overall mortality rate by $25.7 \%$ in the RK and by $16 \%$ in the EKR was observed in progress. It could be partially related with correct consideration of causes of death. Of note, that half of the registered deaths in 2011-2015 yy. in males occurred at the age of $16-62$ years (47.4\% in EKR). Losses of years due to mortality caused by CSD in the EKR tended to decrease (Figure 3).

In the gender aspect, the loss of years due to mortality caused by CSD in males exceeded the loss of years in females by 1.5-1.6 times. In the age aspect, the maximum loss of years was observed between the ages of 70-79 years and 80+ years (Table II). Losses of years at the age group of 60-69 years were 1.3-1.5 times less than at the age group of 70-79 years and 80+ years. In the structure of mortality caused by CSD the leading position had the age group of 60-79 years. The minimum losses of years were recorded at the age of 5-14 years. Similar losses of years were observed at the age groups of 0-4 years and 15-29 years. Losses of years at the age group of 30-44 years were 3.1 times less than at the group of 45-59 years.

According to the nosological aspect, the causes of mortality due to coronary heart disease and cerebrovascular diseases were leading (Table III). Minimal loss recorded due to rheumatic heart disease.

Table II. Losses of years due to mortality caused by CSD ( $\mathrm{M} \pm \mathrm{m} \%$, CI 95\%, fraction in the structure of total mortality in $\%$ ) in the EKR for 2011-2015 yy.

\begin{tabular}{|c|c|c|c|}
\hline Age & Male & Female & Total \\
\hline $0-4$ & $3.6 \pm 3.0 / 0.6-6.5 / 3.0$ & $2.9 \pm 1.6 / 1.4-4.5 / 3.1$ & $3.3 \pm 2.2 / 1.1-5.4 / 3.1$ \\
\hline $5-14$ & $0.2 \pm 0.2 / 0-0.3 / 1.8$ & 0 & $0.1 \pm 0.1 / 0-0.2 / 1.2$ \\
\hline $15-29$ & $4.3 \pm 2.0 / 2.3-6.2 / 6.3$ & $1.7 \pm 0.3 / 1.3-2.0 / 7.5$ & $3.0 \pm 1.1 / 1.9-4.1 / 6.5$ \\
\hline $30-44$ & $34.4 \pm 10.3 / 24.3-44.4 / 19.9$ & $12.4 \pm 2.6 / 9.9-14.9 / 20.9$ & $23.2 \pm 6.2 / 17.1-29.22 / 0.2$ \\
\hline $45-59$ & $109.8 \pm 25.1 / 85.2-134.4 / 35.2$ & $39.7 \pm 7.2 / 32.6-46.8 / 31.4$ & $71.9 \pm 15.2 / 57.0-86.8 / 34.0$ \\
\hline $60-69$ & $214.6 \pm 25.4 / 189.7-239.4 / 38.9$ & $110.9 \pm 17.2 / 94.0-127.7 / 43.3$ & $153.3 \pm 20.0 / 133.7-172.9 / 40.7$ \\
\hline $70-79$ & $272.9 \pm 69.9 / 204.4-341.4 / 41.2$ & $194.2 \pm 50.3 / 144.9-243.5 / 46.5$ & $222.0 \pm 57.1 / 166.1-277.9 / 44.1$ \\
\hline $80+$ & $193.7 \pm 54.2 / 140.6-246.7 / 26.9$ & $203.1 \pm 63.7 / 140.7-265.5 / 29.9$ & $200.6 \pm 61.1 / 140.7-260.5 / 29.1$ \\
\hline Total & $55.7 \pm 11.7 / 44.2-67.2 / 28.6$ & $38.2 \pm 7.5 / 30.8-45.5 / 32.5$ & $46.5 \pm 9.3 / 37.4-55.6 / 30.2$ \\
\hline
\end{tabular}

Table III. Medical and social losses of years according to the nosological group of CSD in the EKR (M \pm m\%o) in the gender and age aspect for 2011-2014 yy.

\begin{tabular}{|c|c|c|c|c|c|c|c|c|c|c|}
\hline \multirow{2}{*}{$\begin{array}{c}\text { Nosological } \\
\text { groups and } \\
\text { units }\end{array}$} & \multicolumn{2}{|c|}{$\begin{array}{c}\text { Fraction of mortality } \\
\text { due to } \mathrm{CSD}, \%\end{array}$} & \multicolumn{2}{|c|}{$\begin{array}{c}\text { YLLs, \%o, 15-29 } \\
\text { years }\end{array}$} & \multicolumn{2}{|c|}{$\begin{array}{c}\text { YLLs, \%o,30-44 } \\
\text { years }\end{array}$} & \multicolumn{2}{|c|}{$\begin{array}{c}\text { YLLs, \%o,45-59 } \\
\text { years }\end{array}$} & \multicolumn{2}{|c|}{$\begin{array}{c}\text { YLLs, \%o, 60-69 } \\
\text { years }\end{array}$} \\
\hline & male & female & male & female & male & female & male & female & male & female \\
\hline $\begin{array}{c}\text { Rheumatic } \\
\text { heart disease }\end{array}$ & 0.9 & 1.6 & $0.2 \pm 0.1$ & $0.2 \pm 0.1$ & $0.4 \pm 0.2$ & $0.4 \pm 0.3$ & $1.3 \pm 0.6$ & $0.9 \pm 0.2$ & $0.9 \pm 0.4$ & $2.8 \pm 0.7$ \\
\hline $\begin{array}{c}\text { Diseases } \\
\text { with arterial } \\
\text { hypertension }\end{array}$ & 5.6 & 6.8 & $0.1 \pm 0.04$ & $0.3 \pm 0.1$ & $1.5 \pm 0.6$ & $0.5 \pm 0.2$ & $7.8 \pm 2.2$ & $4.2 \pm 1.6$ & $12.2 \pm 1.4$ & $9.5 \pm 1.5$ \\
\hline $\begin{array}{c}\text { Ischemic heart } \\
\text { disease }\end{array}$ & 40.9 & 31.7 & $1.0 \pm 0.3$ & $0.3 \pm 0.1$ & $10.9 \pm 2.7$ & $2.5 \pm 0.6$ & $45.9 \pm 6.6$ & $10.1 \pm 1.2$ & $100.6 \pm 8.6$ & $39.1 \pm 5.7$ \\
\hline $\begin{array}{c}\text { Pulmonary } \\
\text { heart }\end{array}$ & 2.5 & 2.4 & $0.3 \pm 0.1$ & $0.2 \pm 0.05$ & $1.1 \pm 0.5$ & $0.8 \pm 0.2$ & $3.4 \pm 0.8$ & $1.8 \pm 0.6$ & $4.2 \pm 0.4$ & $2.4 \pm 1.5$ \\
\hline $\begin{array}{c}\text { Cerebral } \\
\text { and vascular } \\
\text { diseases }\end{array}$ & 29.6 & 42.7 & $0.6 \pm 0.2$ & $0.4 \pm 0.2$ & $7.0 \pm 0.7$ & $3.5 \pm 0.7$ & $27.2 \pm 5.6$ & $15.7 \pm 1.9$ & $68.0 \pm 9.6$ & $44.3 \pm 5.6$ \\
\hline $\begin{array}{l}\text { Diseases of } \\
\text { arteries }\end{array}$ & 2.7 & 2.9 & $0.2 \pm 0.1$ & 0 & $0.6 \pm 0.1$ & $0.4 \pm 0.2$ & $2.5 \pm 0.3$ & $0.9 \pm 0.4$ & $7.4 \pm 1.6$ & $2.9 \pm 1.5$ \\
\hline
\end{tabular}




\section{DISCUSSION}

Comparing the indicators of loss of years due to premature mortality of the employable population as a result of CSD in the EKR, the fraction of direct economic loss was revealed. It decreased from $3.8 \%$ of GDP in the region in $2011 \mathrm{y}$. to $2.3 \%$ in $2014 \mathrm{y}$. Analysis of the total economic loss due to CSD in Russia for 2008-2009 уy. revealed more than 1 trillion rubles loss ( $3 \%$ of Russia's GDP)(8). Thefollowing indicators were taken into account in the analysis (direct costs for hospitalizations, emergency medical calls, outpatient visits, high-tech medical care as well as drug therapy at the outpatient stage of treatment; economical losses as a part of GDP due to mortality in employable population and temporary disability, as well as disability benefits). Only one fifth $(21.3 \%)$ of the total economic loss due to CSD in $2009 \mathrm{y}$. were direct costs of the healthcare system. $78.7 \%$ of the total economic loss due to CSD were indirect costs (economic losses associated with premature mortality of employable male workers). Significant economic loss due to CSD justifies the feasibility of investing more in prevention programs to reduce the risk of CSD and in programs for medical care improvement, to reduce the risk of death in working age (8). The presence of strong inverse correlation between the mortality rate and GDP was established. The significant role of mortality as one of the main causes of decreasing ofhuman potential in the region was revealed. It is caused by droping out of persons from social and economic life (9).

One of the possible reasons of high mortality due to CSD may be adverse ecological conditions of living, particularly associated with the prolonged radioactive fallout due to nuclear weapons tests at the Semipalatinsk polygon. According to researchers from State Medical University of Semei, high riskof arterial hypertension (AH) and coronary heart disease in the first and subsequent generations in population of the EKR and exposed to radiation was revealed (10). However, scientists from Germany, USA, Denmark and Kazakhstan studied population in Semipalatinsk, did not reveale correlation between radiation and risk for mortality due to CSD (11). There was also significanFor comparison, according to the materials of the oncoepidemiological study in the Khabarovsk Territory for 2000-2010. financial and economic losses due to premature mortality due to malignant neoplasms amounted to 18.5 billion rubles [17]. Taking into account financial and economic losses, as a priority area of activity of the oncological service, it is necessary to consider measures for the prevention, screening, optimization of diagnosis and treatment of leading oncological diseases of the digestive system, respiratory system and organs of the female reproductive system and mammary gland. excess of the loss rate due to mortality caused by diseases with high blood pressure in males and females of 30-69 years in EKR compared to Karaganda Region (12).

In 2012 y., 7 million people around the world died from air pollution, including in the WHO European Region. And almost 600000 of deaths were in Kazakhstan. It was an important conclusion of the WHO report dedicated to pathology associated with air pollution (13). These negative consequences were mainly associated with suspended dust particles of air with a diameter of less than 10 microns (PM10 and PM2.5), which caused cardiovascular and respiratory diseases, as well as cancer. According to the "Kazhydromet", in 2015 y. (from the moment of registration) the air in the EKR was mostly polluted with suspended PM2.5 particles. The number of cases of exceeding the maximum permissible concentration (MPC) a year amounted 275 with following increase up to 554 in 2017 y (14).

In order to reduce mortality due to CSD in the Republic of Kazakhstan the Roadmap (to cover the deficit of staff and equipment, advanced training of specialists) and indicators of the medical care quality assessment have been developedas part of implementation of the integrated model of medical care for myocardial infarction and stroke (15-16).

So, for yy. 2011-2014 medical supply with therapeutists per 10000 people amounted 8.8\%oo in the RK, 9.2\%oo in the EKR; medical supply with anesthetists and resuscitation - 1.5\%oo in the RK and $1.5 \%$ oo in the EKR; supply with beds in hospitals - $12.6 \%$ oo in the RK and $16.0 \%$ oo in the EKR; the number of hospital laboratory tests per 100 hospitalized patients in the RK amounted 5101.5, in the EKR - 5095.3.

According to the materials of oncoepidemiological study in the Khabarovsk region for yy. 2000-2010 (Russia), financial and economic losses due to premature mortality due to MN amounted about 18.5 billion rubles [17]. Taking into account financial and economic losses, it is necessary to consider measures for prevention, screening, optimization of diagnosis and treatment of leading oncological diseases of digestive, respiratory, female reproductive systems and mammary glands a priority direction in oncology.

\section{CONCLUSION}

Thus, significant premature loss of years from socially significant diseases in the study region was observed in the group of 45-69 years, with a gender excess of mortality in men. The fraction of direct economic loss from public health losses due to CSD and MN averaged about $5 \%$ of GDP. The medical and 
social losses of years depend on social and economic factors in the region (environmental pollution, population incomes, centralized water supply, and the fraction of economically active population). It requires preventive measures to eliminate the causes of preventable premature mortality and evaluate the strategies of these problems solving.

\section{Conflict of interest}

The authors declared no potential conflicts of interest with respect to the research, authorship and/or publication of this article.

\section{Ethical Approval}

This study was approved by the Medical University of Karaganda Research Ethics Committee.

\section{Funding}

This study was funded by a MH RK.

\section{REFERENCES}

1. Boytsov SA, Samorodskaya IV. Mortality from diseases of the circulatory system in the regions of the Russian Federation (2012). M.: Federal State Budgetary Institution National Medical Research Center for Preventive Medicine of the Ministry of Health of the Russian Federation 2012. URL: https://www.gnicpm. $\mathrm{ru} /$ UserFiles $/ \% \mathrm{D} 0 \% \mathrm{~A} 1 \% \mathrm{D} 0 \% \mathrm{BC} \% \mathrm{D} 0 \% \mathrm{~B} 5 \%$ D $1 \% 80 \%$ D $1 \% 82 \%$ D $0 \%$ B D \% D 0\% B E \% D $1 \% 81 \%$ D $1 \% 82 \%$ D $1 \% 8 \mathrm{C} \% 20$ $\%$ D $0 \%$ B E \% D $1 \% 82 \% 20 \%$ D $0 \% 91 \%$ D0\%A1\%D0\%9A\%204.03.pdf.

2. Sakiev KZ, Ibraeva LK, Dyusembaeva NK, Rybalkina DKh, Drobchenko EA. Qualitative index of population health losses in the Aral Sea Region. Hygiene \& Sanitation 2016; 95 (10): 950-954. doi: 10.18821/0016-9900-2016-95-10950-954. URL:https:/cyberleninka.ru/article/v/ kachestvennyy-pokazatel-poteri-zdorovyanaseleniya-regiona-priaralya.

3. Veisani Y, Jenabi E, Khazaei S, Nematollahi S. Global incidence and mortality rates in pancreatic cancer and the association with the Human Development Index: decomposition approach. Public Health 2018; 156: 87-91. doi: 10.1016/j. puhe.2017.12.015.

4. Novgorodova AV. Lost years of life are an indicator of public health. Narodonaselenie 2015; 2: 74-86. URL: http://www.isesp-ras.ru/images/ narodonaselenie/2015_2.pdf.

5. Belihina TI, Pivina LM, Dyusupov AA, Semenova YM, Manatova AM, CHajzhunusova NZ. Methodological foundations of the organization of medical and environmental studies for assessement of the health status of population in ecologically unfavorable regions of the Republic of Kazakhstan. Nauka i Zdravoohranenie 2017; 5: 29-41. URL: https://newjournal.ssmu.kz/publication/13/ metodologicheskie-osnovy-organizatsii-medikoekologicheskikh-issledovaniy-po-otsenkesostoyaniya-zdo/.

6. URL: http://www.medinfo.kz/\#/dpsobl - "Medical and demographic indicators by regions of the Republic of Kazakhstan from 1990 to the present time" software product for medical organizations and public health authorities. Astana. 2020.

7. Rostovcev VN, Lomat' LN, Ryabkova OI, Marchenkova IB, Kuz'menko VE. Methodology for comprehensive assessment of health losses due to morbidity and mortality. Ministry of Health of the Republic of Belarus (№ 140-1105), The Belarusian Center of Medical Technologies, Informatization, Management and Economics of Public Health. Minsk; 2008. 28 p.

8. Oganov RG, Kontsevaya AV, Kalinina AM. Economic burden of cardiovascular disease in the Russian Federation. Cardiovascular Therapy and Prevention 2011; 4 (10): 4-9. URL: https://elibrary. $\mathrm{ru} / \mathrm{item} . \mathrm{asp} ? \mathrm{id}=16363191$.

9. Mirolyubova TV, and Zubarev NYu. Mortality as an Indicator to Slow Down the Socio-Economic Development in the Region. Ars Administrandi 2017; 1 (9): 16-31. doi: 10.17072/2218-9173-2017-116-31.

10. Tokabaev AK, Zhumambaeva RM, Tokabaeva GT, Dautov DH, Kurumbaev RR. Prevalence of some cardiovascular diseases and their risk factors among the population, which live in territories with radiation effect exposure. Medicine 2014; 10: 24-26. URL:http://www.medzdrav.kz/images/magazine/ medecine/2014/2014-10/M_10-14_24-26.pdf.

11. Grosche B, Lackland DT, Land CE, Simon SL, Apsalikov KN, Pivina LM, Bauer S, Gusev BI. Mortality from Cardiovascular Diseases in the Semipalatinsk Historical Cohort, 1960-1999, and its Relationship to Radiation Exposure. Radiation Research 2011; 176(5): 660-669. https://doi. org/10.1667/RR2211.1.

12. Ibrayeva LK, Rybalkina DK, Zhanbasinova NM, Drobchenko EA. Medical and social losses from diseases of the circulatory system in industrial regions of Kazakhstan. Russian Journal of Occupational Health and Industrial Ecology 2019; 1(7): 444-448. URL: https://doi.org/10.31089/10269428-2019-59-7-444-448.

13. Burden of disease from Household Air Pollution for 2012. Geneva: World Health Organization 2014. URL: http://www.who.int/phe/health_topics/ outdoorair/databases/FINAL_HAP_AAP BoD_24March2014.pdf?ua=1

14. Newsletter on the state of the environment of the Republic of Kazakhstan. Ministry of Energy 
of the Republic of Kazakhstan, Department of Environmental Monitoring, RSE "Kazhydromet", Astana 2015.

15. Аналитический материал расширенной коллегии МЗРК. Астана 03.03.2017. URL: http:// www.rcrz.kz/docs/broshura.pdf.

16. Nogaeva MG, Tuleutayeva SA. Prevalence of cardiovascular disease in Kazakhstan. Medicine 2014; 10: 13-16. URL: http://www.medzdrav. $\mathrm{kz} / \mathrm{images} / \mathrm{magazine} / \mathrm{medecine} / 2014 / 2014$ 10/M_10-14_13-16.pdf.

17. Korneev SM, Kosyh NE. Financial and economic losses as a result of premature mortality due to malignant neoplasms in the population of the
Khabarovsk region. Dal'nevostochnyj medicinskij zhurnal 2012; 4: 51-52. URL: http://www.fesmu. $\mathrm{ru} / \mathrm{dmj} / 20124 / 2012414 . p d f$.

Received: 3.02 .2020

Accepted for publication: 13..07.2020

Address for correspondence:

Dina Kh.Rybalkina

Karaganda Medical University

Department of Internal Medicine

Phone: +7 -747, -387-82-99

E-mail: ystas666@list.ru 